\title{
CAMINHOS PARA AS IDENTIDADES VISUAIS CONTEMPORÂNEAS: ALTERNATIVAS ESTÁTICAS E CAMBIANTES
}

\author{
Lorenzo Ellera Bocchese \\ Universidade Federal do Rio Grande do Sul \\ lorenzo@ellera.com.br
}

\begin{abstract}
Resumo: O contexto tecnológico da atualidade confere profundas e irreversíveis mudanças na política, na economia e nas relações sociais e parece empurrar as artes gráficas para uma constante mudança instantânea e efêmera. A partir desse cenário, o presente trabalho procura entender e avaliar a expressão modernista do design gráfico, caracterizada pela austeridade, clareza e rigidez visual, e sua "perenidade" e colocá-la em paralelo com uma concepção notadamente pós-modernista para identidades visuais, as marcas mutantes, que possuem um aspecto flexível, dinâmico, cambiante e inovador, com a intenção de se perceber se há um conflito entre essas tendências ou se elas se complementam.
\end{abstract}

Palavras-chave: marcas mutantes, identidades visuais, modernismo, pósmodernismo, recursos digitais.

\begin{abstract}
Abstratc: The technological context of the present days confers irreversible and profound changes in politics, economics and social relations and seems to push the graphic arts for a fleeting instant and constant change. From this scenario, this paper seeks to understand and evaluate the expression of modernist graphic design, characterized by austerity, clarity and visual stiffness and its "continuity" and put it in parallel with a noticeably conception of post-modernist visual identities, the mutant brands, which have a flexible, dynamic, changing and innovative aspect with the intent to understand if there is a conflict between these trends or if they complement each other.
\end{abstract}

Keywords: brands mutants, visual identities, modernism, postmodernism, digital resources.

\section{INTRODUÇÃO}

É certo que as tecnologias têm a capacidade de alterar conceitos e percepções da humanidade. A invenção da fotografia, por exemplo, modificou a forma como o 
homem entende o seu entorno e a arte. Atualmente, os recursos digitais são a força transformadora, a computação está invadindo todos os setores da sociedade e tudo está se tornando informatizado, desde o gerenciamento do funcionamento de elevadores em grandes edifícios comerciais, passando pelo controle das roletas no transporte coletivo, até alguns comandos ou sensores em automóveis.

A informática apresenta, a cada semana, lançamentos. Muitas dessas "inovações" são meras variações de um produto com uma nova aparência ou pequenas mudanças no sistema. Contudo, mesmo essas novidades efêmeras podem causar ansiedade e aumentar a sensação de que se está sempre em débito com a tecnologia. Zygmunt Bauman (2007) afirma que a vida atual é uma "vida líquida" por apresentar condições de incerteza constante e que as preocupações decorrentes disso são relacionadas a não se conseguir acompanhar a rapidez das mudanças e ao temor de ficar ultrapassado. Os seguidos reinícios dessa "vida líquida", desencadeados pelas "novidades" tecnológicas, são momentos desafiadores para consumidores, empresas e designers. Para Bauman (2007), o que move uma sociedade líquida é a "modernização", ou seja, "ir em frente despindo-se a cada dia dos atributos que ultrapassaram a data de vencimento [...]. A necessidade é de correr com todas as forças para permanecer no mesmo lugar" (BAUMAN, 2007, pp. 9-10). A análise cáustica de Bauman pede uma reflexão a respeito do desejo que as pessoas têm de sempre estarem em dia com os lançamentos do momento, muitas vezes, com esforços fora de sua capacidade econômica para adquirir novidades tecnológicas que nem sempre serão usadas plenamente.

Essa abordagem sociológica é apenas "o pano de fundo" para analisar como o design gráfico está se manifestando perante as demandas atuais, pois a impressão de que tudo está mudando e se transformando incessantemente reclama uma arte gráfica mais dinâmica, sob pena de a comunicação ficar desalinhada com a ideia de constante "evolução".

As marcas mutantes, aparentemente, são a resposta do design para essa "vida líquida", veloz e maleável. A variação na forma, na cor ou na tipografia dessas identidades visuais vai ao encontro do caráter da sociedade contemporânea, além de representar uma facilidade para a aplicação em suportes eletrônicos, os quais, frequentemente, trazem uma configuração fluida e dinâmica.

Em tempos pós-modernos,

[...] parece haver legitimado a idéia de que é totalmente válido contar com várias formas de uma marca. Mas, qual é o limite? Até quantas versões é razoável se desenvolver? Esta é um pergunta que nem no âmbito profissional nem no âmbito acadêmico tem um resposta consensual (FOROALFA, 2011, ).

Essa dúvida denota que não existe um consenso sobre a eficácia e a usabilidade desse tipo de identidade visual que escapa dos padrões de austeridade, economia visual, rigor e unidade visual preconizados pelos modernistas .

Desse modo, outra questão se impõe: "[...] a uma organização ou a um produto, lhe é mais conveniente ter uma única marca gráfica ou várias versões?" (FOROALFA, 2011).

Debruçado nessa questão, o presente estudo busca pesquisar se há um conflito entre um design gráfico mais rígido, austero e prudente e um design gráfico mais flexível, inexato e cambiante. Com a intenção de entender "[...] o papel do estilo em 
logotipos que embute o seu modo específico de significado" (CALVERA, 2006, p. 108) para as organizações. Para isso, apresenta-se uma definição do que vem a ser esse design rígido e prudente, calcado nos ideais modernistas, e uma definição de design gráfico fluido e cambiante, fundamentado nas concepções pós-modernas, com o intuito de tentar perceber em que medida existe um atrito entre essas metáforas visuais ou se elas acabam por se complementar. Portanto, este trabalho consiste em uma pesquisa de design "[...] com fins de enriquecer sua Teoria e suas práticas" (VAN DER LINDEN, 2010, p. 7).

\section{O DESIGN GRÁFICO MODERNISTA}

"[...] Os homens encaram com hostilidade qualquer valor novo, procurando combatê-lo através da zombaria e da calúnia [...] Zomba-se do valor novo e insultamno. É o lado sinistro da vida" (KANDINSKY, 2008, p. 10). Essa assertiva de Wassily Kandinsky (1866-1944), em um texto escrito em 1912, é atemporal e demonstra o quão revolucionárias eram as propostas visuais dele e de seus pares que compunham os expoentes das vanguardas artísticas do início do século XX. Segundo Rudinei Kopp (2009, p. 29), as vanguardas são "[...] uma série de movimentos artísticos que rompem com o passado".

Kandinsky entendia que "a forma é expressão exterior do conteúdo interior". Afirmava ainda que, se "a forma é apenas uma expressão do conteúdo", logo, "a necessidade cria a forma: certos peixes das grandes profundezas não possuem olhos; o elefante tem uma tromba; o camaleão muda de cor, etc." (KANDINSKY, 2008, p. 11). Segundo Cardoso (2012), esses pensamentos já estavam circulando na Europa desde o século XVIII com o interesse do arquiteto Schinkel (1781-1841) em pesquisar os conceitos da arquitetura grega antiga.

\footnotetext{
A geração de arquitetos de que ele fez parte, os chamado neoclássicos, buscava inspiração na Antiguidade greco-romana e enxergava nas formas de suas qualidades de força, harmonia e beleza. [...] Para eles, era evidente que a questão girava em torno da relação da aparência externa com a estrutura interna. "Forma" seria o resultado de uma tensão entre o interno e o externo, construção e expressão". A boa forma seria aquela que conseguisse externar, de modo feliz e harmônico, 0 significado interior. (CARDOSO, 2012, p. 33).
}

Para Cardoso (2012), essa ideologia deu rumos ao modernismo e preconizava que a "[...] forma seria o resultado de uma tensão entre o interno e externo, construção e expressão" (CARDOSO, 2012, p. 33). A aplicação dessa concepção para o design gráfico ensejou o desenvolvimento de trabalhos com um rigor e clareza matemáticos, com vistas a atingir a sua função: comunicar com objetividade e precisão.

Esses conceitos são o embrião de um modelo visual denominado Estilo Internacional, que é expressão mais contundente do modernismo na arquitetura e nas artes gráficas, tendo sido o movimento predominante na arquitetura ocidental desde na década de 1920 até os anos 1950. No campo do design gráfico, ele teve seu apogeu um pouco depois, entre as décadas de 1950 e 1960, pregando clareza, objetividade e rigor matemático (AMBROSE; HARRIS, 2009; HOLLIS, 2006; MEGGS; PURVIS, 2009; WOLLNER, 2003), e ensejou um refinamento das artes gráficas, tanto na esfera estética 
como no desenvolvimento de recursos tecnológicos. Oportunizou, por exemplo, o surgimento de um design gráfico corporativo mais direto, objetivo, assim como a criação dos hoje amplamente utilizados manuais de identidade visual (MEGGS; PURVIS, 2007).

Além da visão estética mais racional e pragmática, o contexto político também concorreu para o recrudescimento do Estilo Internacional. A visão nacionalista que desencadeou as duas Guerras Mundiais foi contestada por meio das artes plásticas, da arquitetura e também do design gráfico, que propunham a negação dos modelos artísticos com características regionais. Esse posicionamento ideológico ensejou trabalhos gráficos que buscavam uma comunicação universal sem vínculos localistas. Consequentemente, os layouts passam a ter como característica mais marcante uma evidente economia visual, austeridade, clareza e, principalmente, neutralidade, abolindo os ornamentos e os decorativismos, visando encontrar um aspecto internacionalista. Conforme Kahn, a expressão Estilo Internacional surgiu em 1932:

[...] inventada por Henry-Russel Hitchcock e Philip Johnson em 1932, caracterizava as facetas prevalecentes da arquitetura moderna como estava a ser executada na Europa por Le Corbusier e membros da Bauhaus, entre outros. Na sua descrição de Estilo Internacional. [...] O Internacionalismo foi uma maneira de funcionar num mundo que se globalizava, e a arquitetura internacionalista - ou seja, a arquitetura sem raízes num lugar, transmissível a todas as zonas do mundo e encarnando princípios modernos e universais - começou a prevalecer. (KAHN, 1999, p. 8).

Entre os movimentos de vanguarda artística, o que mais deu substrato ao Estilo Internacional foi o De Stijl. Gestado na Holanda, no final da década de 1910, no contexto da Primeira Guerra Mundial, teve como articuladores Theo van Doesburg (1883-1931), Piet Mondrian (1872-1944), Bart Anthony van der Leck (1876-1958), Vilmos Huszár (1876-1958), e Jacobus Johanner Pieter Oud (1890-1963). Eles preconizavam uma arte ideal, geométrica, abstrata e regrada por leis universais de equilíbrio e harmonia (MEGGS; PURVIS, 2007). Esses artistas, embora fizessem uma arte de viés geométrico e racional, cultivavam um forte aspecto espiritual, pois acreditavam em uma "verdade absoluta", que pretendiam expressar por meio de suas obras.

Carlos Leite Brandão escreve, no prefácio do livro Neoplasticismo na pintura e na arquitetura, de Piet Mondrian (2008), que as pinturas desse artista exploram

[...] cores e conexões equilibradas entre vários elementos construtivos, pois só elas podem gerar beleza pura e a força universal condizentes com o espírito absoluto, como, por exemplo, equilibrando-se horizontais e verticais, vastos espaços vazios e reduzidas superfícies coloridas. (MONDRIAN, 2008, p. 22).

Mondrian, na primeira década do século XX, deslocara o seu olhar das formas aparentes para a estrutura geométrica e abstrata. Ele buscava o máximo de clareza e de universalidade, visando a uma arte "única e verdadeira". Suas pinturas instituem uma nova estética cosmopolita que inspiraria os trabalhos gráficos modernistas nas décadas seguintes.

A Bauhaus foi outra fonte para os conceitos do Estilo Internacional. Criada em 1919 e fechada pelos nazistas em 1933, teve como mentor e primeiro diretor o lendário arquiteto Walter Gropius (1883-1969). A escola tinha como objetivo aproximar artistas e artesãos, artesanato e indústria, arte e o que hoje chamamos de design, além de colocar em prática uma visão diferenciada de produção, mais racional 
e científica, fomentando a tessitura entre artistas e o sistema industrial (AMBROSE; HARRIS, 2009) e criando "[...] um movimento viável e moderno de design, abrangendo arquitetura, design de produto e comunicação visual” (MEGGS; PURVIS, 2009, p. 414). $\mathrm{Na}$ Bauhaus, Gropius chamou alguns dos mais importantes artistas da Europa - tais como Paul Klee (1879-1940), Vassily Kandinsky (1866-1944) e Laszlo Moholy-Nagy (1895-1946) - para lecionar pintura, escultura, teatro, arquitetura e desenho gráfico. $O$ "[...] treinamento em oficinas altamente engajadas com a produção, complementado com um profundo aprendizado teórico sobre as leis do design" (GROPIUS apud RICKEY, 2002, p. 63), fazia dos discentes da escola profissionais altamente qualificados e conectados com a sociedade.

Isso tudo desembocaria em uma concepção funcionalista e de extrema limpeza visual na arquitetura e no design gráfico, Cardoso aponta que esse ideal (funcionalista) está relacionado

[...] a uma fórmula estilística e a preceitos do modernismo internacional, sendo os principais: a ausência de ornamento; o despojamento de sua estrutura; a correspondência de sua configuração à geometria euclidiana; e a restrição da paleta de cores, com predileção por cores sólidas ou primárias" (CARDOSO, 2012, p. 102).

Os trabalhos de Karl Gerstner, que foi discípulo do pintor, designer gráfico e arquiteto Max Bill (1908-1994), expressam esse caráter. Gerstner era "[...] pintor da escola pós-construtivista suíça, a escola de artistas 'concretistas' que usavam sistemas e ideias matemáticas" (HOLLIS, 2005, p. 133). A aplicação de um rigoroso grid na página é, até hoje, um dos emblemas maiores do design gráfico modernista e acreditase que esse método tenha sido introduzido durante os anos da Bauhaus (HOLLIS, 2005).

Além de uma visão matemática, o design gráfico modernista também traz no seu arcabouço a predominância do uso de tipografias sem serifa, a utilização de linhas perpendiculares, a assimetria e uma redução das formas. Isso tudo com a intenção de adequar a forma ao propósito, ou seja, à comunicação universal (internacional), como aponta Kopp:

[...] O Estilo Internacional originário na Suíça e Alemanha tornou-se, de fato, internacional. Muitos designers e empresas adotaram os princípios funcionalistas e organizaram suas estratégias de comunicação visual em cima desse paradigma. Sua influência é percebida ainda hoje e não há mais como pensar a identidade corporativa sem lembrar seus fundamentos, seja para aplicá-los, seja para rejeitálos. (KOPP, 2009, p. 72).

Kopp (2009) afirma que, em certa medida, o modernismo procurava um ideal de pureza, eliminando tudo o que fosse híbrido, e que isso vai de encontro à natureza das coisas. Essa assertiva coloca uma indagação aos preceitos do modernismo: seria um movimento por demais artificial e desumano? Sua concepção estática e geométrica conseguiria traduzir as emoções que um marca ou um anúncio pretende externar?

\section{O DESIGN GRÁFICO PÓS-MODERNISTA}

O design gráfico atual é marcado pela estética pós-moderna, com peças gráficas saturadas, híbridas, multicoloridas e, muitas vezes, pautadas pelo excesso, deixando 
para um segundo plano a austeridade do modernismo (MEGGS; PURVIS, 2009). Observando os trabalhos de David Carson (1956), Stefan Sagmeister (1962), Neville Brody (1957) e Paula Scher (1948) (figura 1), consagrados designers gráficos da atualidade, pode-se perceber que seus layouts são desenvolvidos nessa concepção, ou seja, suas propostas espelham o temperamento contemporâneo, que é marcado pela heterodoxia, pela liberdade visual e pela quebra de paradigmas.

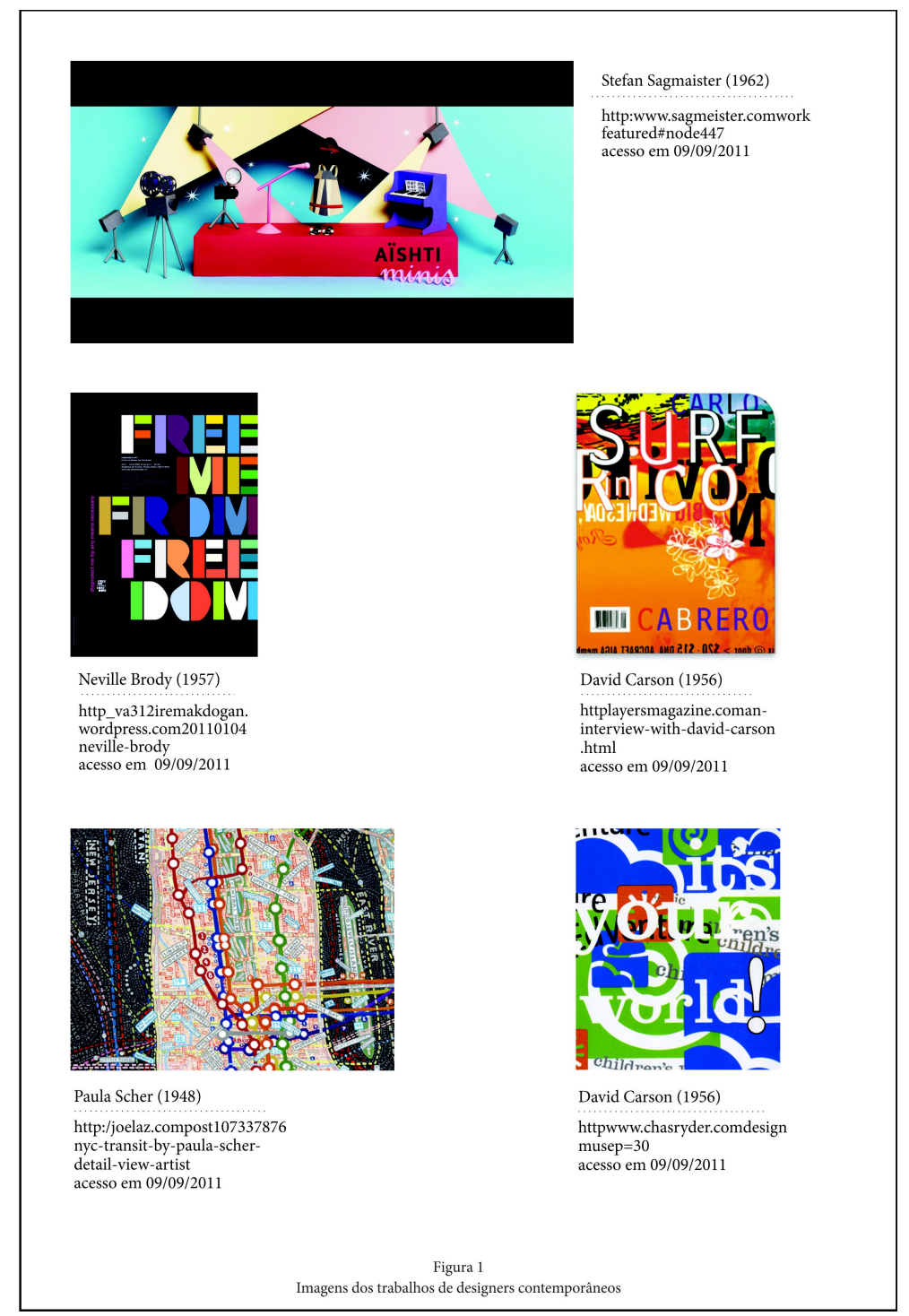

Contudo, Hollis afirma que "[...] ao longo de vários séculos, as funções básicas das artes gráficas sofreram tão poucas alterações quanto o alfabeto romano" (HOLLIS, 2005, p. 4), ou seja, as funções intrínsecas do design gráfico, que são: identificar, informar, apresentar, permanecem inalteradas. 0 autor alerta que, mesmo com o desenvolvimento de novas formas e formatos para atender às atualizações dos recursos tecnológicos, os avanços nessa área são "[...] surpreendentemente localizados [...] e associadas a pioneiros isolados e o design gráfico continua a se alimentar de suas próprias tradições". Hollis chama a atenção que, com o vasto banco de imagens e 
informações hoje disponível a todos, os trabalhos em sua essência acabam sendo muito semelhantes.

Embora muitas imagens sejam criadas pelos próprios designers, grande parte delas são imagens prontas, como as antigas xilogravuras reaproveitadas pelos tipógrafos medievais de trabalhos anteriores, as antigas gravuras ou as fotografias do acervo de uma agência de imagens (HOLLIS, 2005, p. 4).

Sagmeister pode ser considerado um desses inovadores isolados, pois ele vem apostando no desenvolvimento e na aplicação das marcas mutantes, como, por exemplo, as marcas da Casa da Música de Portugal e da EDP (figuras 2 e 3). Todavia, corroborando as colocações de Hollis, Meggs e Purvis afirmam que conceito de marca flexível já aparecia de modo embrionário na década de 50 com a marca da CBS:

[...] A aplicação dessa marca aos impressos da CBS, desde etiquetas de remessa até comunicados à imprensa, era feita com atenção e cuidado. Mas a coerência dogmática no modo de usar a marca não era considerada necessária. Ela era usada com diversas versões da assinatura da empresa, e Golden e sua equipe evitavam empregá-la onde não era cabível. [...] O enfoque da CBS para a imagem e design corporativos não dependia de um sistema ou estilo, mas sim da política gerencial em relação ao design e ao talento criativo de seu pessoal. A vantagem dessa diretriz é um projeto corporativo variado e dinâmico, que pode mudar em função das necessidades da empresa e evolução das sensibilidades; o perigo potencial é a falta de alternativa caso a responsabilidade pela gestão ou pelo design passe para mãos menos astutas (MEGGS, 2009, p. 525).
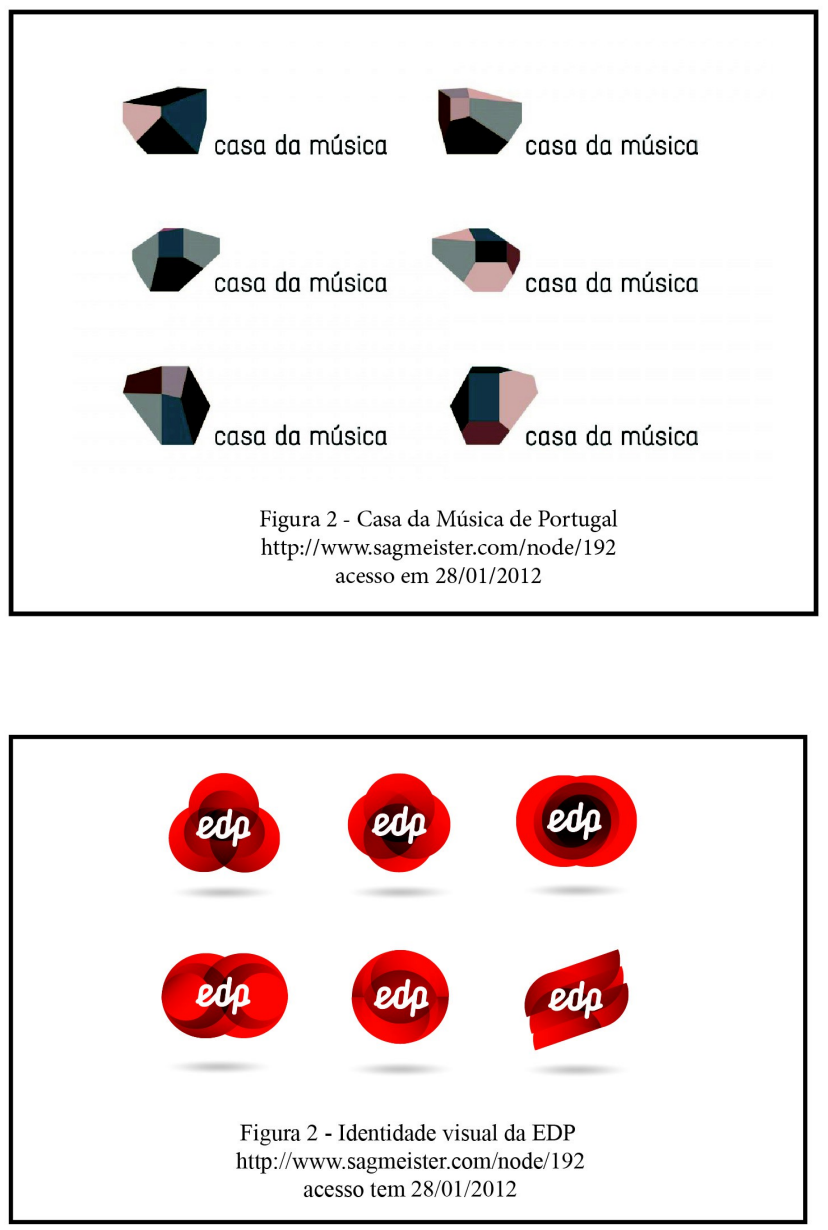
O design gráfico, mais do que nunca, está um momento de valorização do movimento, da dinâmica e, por consequência, está rompendo com os padrões elaborados ao longo do século XX.

As pessoas hoje desejam a "[...] informação instantânea, efêmera, mutante, cambiante, configurada ao sabor dos parâmetros pessoais de cada cliente ou usuário [...]", assim, design contemporâneo se "[...] caracteriza pela sua natureza irrequieta, efêmera e cambiante. Ele é a reação intuitiva da nova geração de designers aos excessos racionalistas e positivistas dos programadores visuais do pós-guerra" (CAUDURO, 2009, p. 17).

Essa oposição começa ao final dos anos 1950, quando o mundo entra em uma era pós-moderna, pós-industrial, e a Europa já está quase toda reconstruída.

A partir desse momento, o discurso científico moderno começa a ser questionado.
[...] O quadro que se desenha a partir das décadas de 1960 e 1970 , especialmente,
cria condições para pensar o mundo ocidental a partir de uma matriz diferente da
modernidade do começo do século. Expressões e debates em torno da cultura
(arquitetura, pintura, literatura, cinema, música, etc.) estendem-se no campo da
filosofia, economia, política, antropologia, sociologia. [...] A ideia da pós-
modernidade começa a ser debatida (KOPP, 2009, p. 31).

Kopp ilustra que, se a imagem emblemática dos tempos modernistas eram as chaminés das indústrias e sua produção fordista seriada, os “[...] escritórios e a indústria da informação são as imagens da era contemporânea, pós-moderna ou modernamente tardia" (KOPP, 2009, p. 35). Isso significa, em termos práticos, uma substituição de modelo no qual as coisas (inclusive as carreiras profissionais) tinham um começo, meio e fim definidos para o conceito de total instabilidade e mutação dos dias de hoje. Desse modo, "[...] poucos termos traduzem, por enquanto, tão bem a estética de nosso tempo como flexibilidade" (KOPP, 2009, p. 37). Dessa "flexibilidade" decorrem outros "[...] adjetivos como [...] transitório, fugidio, cambiante, liquefeito, fragmentado" (KOPP, 2009, p. 93).

As marcas mutantes, por sua vez, são a expressão gráfica dessas qualidades, sendo fruto, em grande medida, da evolução constante dos recursos digitais que ensejam a criação, a produção e a aplicação de marcas com estruturas flexíveis. Essas identidades visuais carregam o lema do nosso tempo, que, segundo Bauman, é a flexibilidade.

[...] todas as formas devem ser maleáveis, todas as condições, temporárias, todos os formatos, possíveis de remodelagem. Reformar, de modo obsessivo e devotado, é tanto um dever quanto uma necessidade. Para a sociedade de consumidores - e para o mercado de consumo, seu alicerce e direção -, essa é uma circunstância favorável; na verdade é a garantia de sobrevivência (BAUMAN, 2005, pp. 124, 125).

Jorge Frascara (2006) reforça o influxo das tecnologias no design gráfico e coloca que o advento do computador teve interferência, tanto na produção, eliminando boa parte do processo "braçal" ou manual, quanto na criação, trazendo acesso e interação com uma multiplicidade de informações. Além disso, design gráfico teve de dar conta da transmissão da informação de modo fluido e atraente dentro dos suportes digitais e com isso "uma nova série de problemas" (FRASCARA, 2006, p. 173) se apresentou aos designers, como, por exemplo, a usabilidade e a facilidade de navegação em um site ou dispositivo eletrônico, pois é fundamental que o usuário 
tenha clareza de parte do site em que ele se encontra, de onde que ele veio e para onde ele pode ir (FRASCARA, 2004).

A fusão da uma visão mutante, híbrida e multicultural, decorrente do contexto pós-moderno, com a evolução dos recursos digitais (tanto para a criação como para a visualização de conteúdo) e a "necessidade" das pessoas de estarem sempre "atualizadas" com os padrões tecnológicos e estéticos, é um terreno fértil para a "[...] sedução e o efêmero tornarem-se, [...], princípios organizadores da vida coletiva moderna, vivemos em sociedades de dominante frívola" (LIPOVETSKI, 1989, p. 27). Esse caráter denota um comportamento de busca pela singularidade, "[...] a luta pela singularidade agora se tornou o principal motor da produção e do consumo de massa [...] A singularidade agora é marcada e medida pela diferença entre 'o novo' e 'o ultrapassado"' (BAUMAN, 2005, p. 36). Evidentemente que as marcas e as organizações não ficam de fora desse jogo perverso de busca pelo "novo".

A questão que fica é: será que essa constante flexibilização da estética visual das organizações e a profusão de mídias e suportes para a visualização de conteúdo não acaba por tornar a comunicação confusa e imprecisa?

\section{CONCLUSÃO}

Rígido ou flexível?

Essa dicotomia pode ser amortecida por um caminho do meio, que aponta para uma parcimônia tanto no uso dos eficientes e pragmáticos preceitos do modernismo quanto na maleabilidade dos trabalhos "excessivos" do pós-modernismo e, com isso, uma confluência dessas ideologias estéticas. Pereira corrobora esse caminho intermediário ao preconizar "um modelo de comunicação" que possa estar "marcado por uma compreensão não redutora" (PEREIRA, 2011 p. 177).

McLuhan indicava que "[...] o artista pode corrigir as relações entre os sentidos antes que o golpe da nova tecnologia adormeça os procedimentos conscientes" (MCLUHAN, 1964, p. 86), ou seja, o artista pode perceber as novas ondas estéticas e sociais que estão por vir, e o designer, por sua vez, deve ter a mesma sensibilidade aguçada. Contudo, essa qualidade é direcionada para resolver os trabalhos de seus clientes, funcionando com uma antena que capta as ondas de transformação. Os designers e os artistas dos anos 70 e 80 estavam ocupados em se opor às ideias de austeridade do modernismo; portanto, a força propulsora daquele momento era a renovação e as suas "antenas" estavam conectadas no devir.

Hoje, segundo Noble e Bestley (2011), o que transforma o design são os recursos digitais (não mais um ideário revolucionário). Eles afirmam, inclusive, que "a forma segue a tecnologia" (NOBLE; BESTLEY, 2011, p. 164). Os autores destacam que essas mudanças ensejadas pelas tecnologias não são algo tão novo, pois a história das artes gráficas está umbilicalmente ligada ao desenvolvimento dos processos de impressão, desde os tipos móveis até a impressão digital. Portanto, hoje são a internet e os dispositivos móveis que oportunizam uma nova experiência de relacionamento com a informação e mudanças nos conceitos de o que é um bom design (NOBLE; 
BESTLEY, 2011), ou seja, "[...] cada nova tecnologia produz mudanças na estética do design gráfico contemporâneo"1 (NOBLE; BESTLEY, 201, p. 164).

Frascara (2004) afirma que o design gráfico está em sua terceira geração. A primeira surge entre nos anos 1920, estando relacionada a um refinamento da estética aplicada às artes gráficas; a segunda se dá na década de 1950, com a aplicação da psicologia, da sociologia e do marketing na comunicação visual. Na fase atual, o design está sustentado pela tecnologia, o que resulta em um maior diálogo entre emissor e receptor.

Com isso, as marcas mutantes podem desencadear um maior grau de interação, permitindo, por exemplo, que o cliente escolha o seu produto com determinada versão da marca. Ademais, por terem a flexibilidade e a mobilidade na sua essência, também permitem uma maior sedução junto aos receptores, pois "[...] o movimento é a atração visual mais intensa da atenção [...] Os seres humanos [...] são atraídos pelo movimento; basta mencionar a efetividade dos anúncios móveis" nas ruas das cidades (ARNHEIM, 2007, p. 365).

As marcas convencionais, por sua vez, inscritas dentro dos conceitos do modernismo, mais precisamente do Estilo Internacional, que tem seu valor na manutenção de uma forma estável e austera, conferem à organização um sentimento de solidez, ordenação e austeridade.

Desse modo, percebe-se que não existe, universalmente falando, um melhor caminho. O que pode determinar a melhor alternativa são o segmento de atuação da empresa e o público a que a identidade visual se destina. As marcas mutantes, por se tratarem de uma estrutura de identidade visual muito inovadora, arrojada e instável, não são indicadas para empresas que possuam valores austeros, conservadores ou que precisem expressar uma ideia de segurança, estabilidade ou solidez. Aqui, podem-se citar dois exemplos básicos: escritórios de advocacia e a indústria automobilística. Esses dois setores de negócios precisam, invariavelmente, conferir, por meio de sua marca, segurança e estabilidade. Kreutz (2005) aponta que o "[...] objetivo da organização e o repertório do público são dois fatores que poderão determinar a escolha de um ou outro tipo de identidade visual" (KREUTZ, 2005, p. 169). Kreutz afirma, também, que os segmentos de entretenimento, tecnologia, esporte, arte e outros produtos ou serviços direcionados aos jovens são os mais indicados para a utilização das marcas mutantes. A autora aponta, ainda, que, por elas estarem ligadas às tendências da contemporaneidade, são fruto da evolução das comunicações e, portanto, dos recursos tecnológicos.

Por fim, mesmo que alguns autores preconizem que "do 'mundo verdadeiro' da modernidade só restam ruínas, mas sobre estas ruínas se erguem novas tábuas de valores. A pós-modernidade é terra firme para a proliferação do efêmero" (MARTINS, 2008 , p. 75), o legado do modernismo continua presente no design gráfico e a escolha entre o flexível, o efêmero ou o rígido e duradouro será determinada pelos valores e pelos objetivos da organização e, principalmente, o seu público-alvo. Frascara (2005) fortifica essa assertiva ao afirmar que a essência do design "[...] não é a criação de formas, mas a criação de uma comunicação eficaz" e que o "[...] o significado da

1 Tradução livre do autor, no texto original: "each new technology has seen a shift in contemporary graphic design aesthetics". 
mensagem deve estar relacionado com o interesse público" (FRASCARA, 2006, pp. 24 67).

Assim, o que vai determinar se uma organização deve optar por uma marca pós-modernista ou por uma marca modernista serão o setor econômico de atuação e a identificação do seu público com conceitos mais arrojados ou mais conservadores. Respondendo, desse modo, às questões que finalizam os capítulos 2 e 3: sim, uma marca estática e geométrica pode conferir qualidades positivas a uma corporação e uma marca mutante, se aplicada em um segmento de negócio compatível com a flexibilidade, pode ser uma eficiente ferramenta de comunicação.

\section{REFERÊNCIAS}

AMBROSE, Gavin; HARRIS Paul. Dicionário visual de design gráfico. Porto Alegre: Bookman, 2009.

ARNHEIN, Rudolf. Arte e percepção - Uma psicologia da visão criadora. São Paulo: Thomson Learning. 2007.

BANN, David. Novo manual de produção gráfica. Porto Alegre: Bookman, 2010

BAUMAN, Zygmunt. Vida líquida, Rio de Janeiro: Jorge Zahar. 2007

CALVERA, Anna. Treinando pesquisadores para o design: algumas considerações e muitas preocupações acadêmicas. Revista Design em Foco, Salvador, jan. - jun., vol. III, n. 001. pp. 97-120.

CARDOSO, Rafael. Design para um mundo complexo. São Paulo: Cosac Naify, 2012.

CAUDURO, Flávio Vinícuis. Apresentação. In: KOPP, Rudinei. Design gráfico cambiante. 3. ed. Santa Cruz do Sul: EDUNISC, 2009. pp $15-20$

FOROALFA. Disponível em: <http://foroalfa.org/articulos/para-que-sirven-las-marcasmutante>. Acesso em: 24 mar. 2012.

FRASCARA, Jorge. Communication design: Principles, methodos, ans pratice. New York: Allworth Press. 2005

El disegno de comunicacion. Buenos Aires: Ediciones Infinito. 2006

HOLLIS, Richard. Design gráfico: uma história concisa. São Paulo: Martins Fontes, 2005.

Swiss graphic design: the origins and growth of an International Style 19201965. New Haven: Yale University Press, 2006.

KAHN, Hassan-Uddin. Estilo Internacional. Köln: Taschen, 1999.

KANDINSKY, Wassily. Gramática da criação. Lisboa: Edições 70, 2008. 
KOPP, Rudinei. Design gráfico ambiante. 3. ed. Santa Cruz do Sul: EDUNISC, 2009.

KREUTZ, Elizete de Azevedo. Identidade visual mutante : uma prática comunicacional da MTV. Tese (Doutorado), FAMECOS. PUC-RS, Porto Alegre, 2005. LIPOVETSKY, Gilles. O império do efêmero. São Paulo: Cia das Letras, 1989

MARTINS, Francisco Menezes. Impressões digitais - Cibercultura, comunicação, e pensamento contemporâneo. Porto Alegre: Meridional, 2008.

McLUHAN, Marshal. Os meios de comunicação como extensões do homem. 4. ed. São Paulo: Pensamento-Cultrix, 1974.

MEGGS, Philip; PURVIS, Alston W. História do design gráfico. 4 ed. São Paulo: Cosac e Naify, 2009.

MONDRIAN, Piet. Neoplasticismo na pintura e na arquitetura. São Paulo: Cosac e Naify, 2008.

NOBLE, Ian; BESTLEY, Russel. Visual resarch: an introduction to resarch. Lausane: AVA Publishing SA. 2011.

PEREIRA, Vinícius Andrade. Estendendo McLuhan: da aldeia à teia global Comunicação, memória e tecnologia. Porto Alegre: Sulina, 2011.

VAN DER LINDEN, Júlio Carlos de Souza . Uma taxonomia para a pesquisa em design. In: 9o Congresso Brasileiro de Pesquisa e Desenvolvimento em Design, 2010, São Paulo. Anais do P\&D 2010, 2010.

WOLLNER, Alexandre. Design visual. São Paulo: Cosac e Naify, 2003. 